\title{
TRAUMATIC EXTRADURAL HEMATOMA
}

Training Medical Officer Department of Neurosurgery, PGMI/HMC, Peshawar drmiulhaq@gmail.com

Correspondence Address: Mian Iftikhar ul haq

Trainee Medical Officer Department of Neurosurgery PGMI/HMC, Peshawar drmiulhaq@gmail.com

\author{
Mian Iftikhar ul Haq
}

\begin{abstract}
Objectives: To determine the frequency, clinical presentation and outcome of extradural hematoma in patients with head injury. Study Design: Cross sectional descriptive study. Setting: Neurosurgery department of Hayatabad Medical Complex, Peshawar. Period: $1^{\text {st }}$ January 2011 to $1^{\text {st }}$ July 2012. Patients and methods: All patients of head injury, from all ages and both genders were included. Patients in whom EDH caused by bleeding disorders or vascular malformations of the dura mater and post surgical EDHs were excluded from the study. CT scan brain was done for all patients to confirm their diagnosis. The information regarding patient demographical details, clinical presentation and site and size of hematoma was documented in patient's Performa. The data was analyzed by SPSS version 16. Results: A total of 331 patients with head injuries were included in the study. Out of 331 patients, there were $221(66.76 \%)$ males and $110(33.23 \%)$ females. Majority of patients $90(27.2 \%)$ were in the age range of 21-30 years. $\mathrm{EDH}$ was found in $29(8.76 \%)$ patients. The commonest location of extradural hematoma was temporo-parietal region i.e 3.93\%. One patient had left side weakness postoperatively and two $(6.89 \%)$ died. Conclusions: The outcome of operated extradural hematoma patients was good in those patients having higher GCS score
\end{abstract}

Key words: Outcome, Head injury, Extradural hematoma.

Article received on: $10 / 07 / 2013$

Accepted for Publication: $15 / 01 / 2014$

Received after proof reading $31 / 05 / 2014$

Article Citation: Mian Iftikhar ul Haq. Traumatic extradural hematoma. Professional Med $J$ 2014;21(3): 540-543.

\section{INTRODUCTION}

Among trauma patients, head injury is responsible for up to $50 \%$ of fatalities and for a large component of continuing care among survivors. Head injury remains the most common cause of death and disability in young people $e^{1,2}$.

Epidural haematoma (EDH) is a potentially lifethreatening complication after severe traumatic brain injury (TBI). However, it also occurs after mild or moderate $\mathrm{TBI}^{3,4}$. $\mathrm{EDH}$ is characterized by a variable clinical presentation in the acute situation $^{2,4,5}$. If undetected and untreated the $\mathrm{EDH}$ may lead to progressive transtentorial herniation with loss of consciousness, pupillary dilation, and further neurologic deficits ${ }^{1,5,6}$.

EDH results from interruption of dural vessels, including branches of the middle meningeal arteries, veins, dural venous sinuses, and skull vessels $^{2,3,6}$. CT scanning is the most accurate, investigation of choice for the diagnosis of EDH and it will show the typical biconvex or lens shaped hyperdense lesion. Several types of head injury are amenable to neurosurgical intervention, and improved outcomes have been reported in patients receiving prompt treatment of posttraumatic extra-axial cerebral mass lesions, including EDHs and $\mathrm{SDHs}^{5,7,8}$. My study objective was to determine the frequency, clinical presentation and outcome of extradural hematoma in patients with head injury.

\section{MATERIAL AND METHODS}

This cross sectional descriptive study was done in neurosurgery department of Hayatabad Medical Complex, Peshawar, from from 1st January 2011 to $1^{\text {st }}$ July 2012. A total of 331 patients of head 
injury, of various ages and both genders were included. Patients in whom EDH caused by bleeding disorders or vascular malformations of the dura mater and post surgical EDHs were excluded from the study. CT scan brain was done for all patients to confirm their diagnosis. The information regarding patient demographical details, clinical presentation and site and size of hematoma and site of skull fracture was documented in patient's Performa. The data was analyzed by SPSS version 16. Frequency and percentage was calculated for categorical variables. Mean $\pm S D$ was calculated for age. Results were presented as tables.

\section{RESULTS}

Out of 331 patients, there were $221(6.76 \%)$ males and $110(33.23 \%)$ females In this study the mean age was $29 \pm 1.2$ years SD. Majority of patients $90(27.19 \%)$ were in the age range of $21-30$ years (Table I).

\begin{tabular}{|c|c|c|}
\hline Age (years) & Number & Percentages \\
\hline $0-10$ & 38 & 11.48 \\
\hline $11-20$ & 52 & 15.7 \\
\hline $21-30$ & 90 & 27.19 \\
\hline $31-40$ & 64 & 19.33 \\
\hline $41-50$ & 54 & 16.31 \\
\hline $51-60$ & 20 & 6.04 \\
\hline Above 61 & 13 & 3.93 \\
\hline & Table-I. Age distribution \\
\hline
\end{tabular}

Glasgow coma scale was used to assess the level of consciousness. Most of the patients $160(48.34 \%)$ had GCS in the range of 13 to 15 (Table II)

\begin{tabular}{|c|c|c|}
\hline GCS Score & Number & \%age \\
\hline $3-8$ & 49 & 14.8 \\
\hline $9-12$ & 122 & 36.86 \\
\hline $13-15$ & 160 & 48.34 \\
\hline \multicolumn{2}{|c|}{ Table-II. Glasgow coma scale } \\
\hline
\end{tabular}

The commonest presentation was headache i.e. 242 patients $(73.11 \%)$ and 210 patients (63.44\%) had vomiting as presenting complaints (Table III).

Out of 331 patients extradural hematoma was found in 29 patients (8.76\%). The commonest location was temporo-parietal region i.e. 13 (3.93\%) patients (Table IV).

\begin{tabular}{|l|c|c|}
\hline Clinical features & Number & \%age \\
\hline Headache & 242 & 73.11 \\
\hline Vomiting & 210 & 63.44 \\
\hline Loss of consciousness & 111 & 33.53 \\
\hline Focal neurological & 85 & 25.67 \\
\hline \multicolumn{2}{|r|}{ Table-III. Clinical presentation } \\
\hline
\end{tabular}

\begin{tabular}{|l|c|c|}
\hline Site of hematoma & Number & \%age \\
\hline Temporal - parietal & 13 & 3.93 \\
\hline Parietal & 9 & 2.72 \\
\hline Frontal & 5 & 1.51 \\
\hline Posterior fossa & 2 & 0.6 \\
\hline Total & 29 & 8.76 \\
\hline \multicolumn{2}{|c|}{ Table-IV. Distribution of hematoma } \\
\hline
\end{tabular}

\section{DISCUSSION}

Head injuries are common in younger age groups. People in their twenties and thirties are having higher chances of sustaining head traumas ${ }^{3,7}$. Because at this age groups they work hard and remain prone to the road traffic accidents, industrial hazards and of course physical violence. In the present study, the commonest age group is 21 to 30. Naveed D also reported the same results $^{9}$. Rehman $L$ showed the common age group $20-30$ years in his study ${ }^{10}$. Khan MJ repoted the common age group less then 12 years ${ }^{11}$.

Males are more commonly effected in the current study. The reason is the nature of jobs, higher risk of trauma and warfare injuries. Naveed D also observed male effected more in head trauma. ${ }^{9}$ Cheung PS showed male dominency in his study $^{12}$. Khan MJ also reported male effected more 
in his study ${ }^{11}$.

The predominant complaints in our patients were headache $242(73.11 \%)$ and vomiting $210(63.44 \%)$. Headache in head injury patients is significant because headache may be due to underlying raised intracranial pressure. Vomiting is another important symptom in head injury patients. There can be several reasons for vomiting in head injury patients which include raised intracranial pressure, disturbance of vestibulocholear system swallowing of blood. Naveed $D^{9}$ etal and Rehman $L^{10}$ etal also reported the same sequences of clinical features. Cheung PS etal showed that headache and vomiting is the commonest clinical features in his study ${ }^{12}$.

Majority of the patients in this study were in minor head injury i.e. 160(48.34\%). Cheung PS reported similar results in his study ${ }^{12}$. Rehman $L$ also showed same pattern of GCS score ${ }^{10}$. Khan MJ reported more commm GCS score of the patients were in the mild i.e 13-15 ${ }^{11}$.

In our study the frequency of extradural hematoma was $29(8.76 \%)$. Naveed D et al has reported $47(23.86 \%)$ in his study ${ }^{9}$. Cheung PS has observed $8.24 \%$ of extradural hematoma in head trauma patients $^{12}$. Leitqeb $\mathrm{J}$ reported $21.5 \%$ of patients have $\mathrm{EDH}$ after sustaining head trauma ${ }^{13}$.

The commonest site of extradural hematoma was temporoparietal in my study i.e $3.93 \%$, while parietal in $2.72 \%$, frontal in $1.51 \%$ and Posterior fossa involvement in $0.6 \%$ of cases. Steinen $M$ showed that the temporoparietal $\mathrm{EDH}$ is the commonest area ${ }^{14}$. Rehman $L^{10}$ and Naveed $D^{9}$ also reported the same sequences of EDH distribution.

Most of our patients 26(89.65\%) have good postoperative outcome. One patient had left side weakness postoperatively and two (6.89\%) died due to low GCS score i.e 3. Three (10\%) patients had died in a study conducted by Rehman $\mathrm{L}^{10}$. Cheung PS reported $10 \%$ mortality in his study ${ }^{12}$.

\section{CONCLUSIONS}

The outcome of operated extradural hematoma patients was good in those patients having higher GCS score.

Copyright(C) 15 Jan, 2014.

\section{REFERENCES}

1. Paiva WS, Andrade AF, Mathias Junior L, Guirado VM, Amorim RL, Magrini NN, Teixeira MJ. Management of supratentorial epidural hematoma in children: report on 49 patients. Arq Neuropsiquiatr 2010;68:888-92.

2. Klemenc-Ketis Z, Bacovnik-Jansa U, Ogorevc M, Kersnik J. Outcome predictors of Glasgow Outcome Scale score in patients with severe traumatic brain injury. Ulus Travma Acil Cerrahi Derg 2011;17:509-15.

3. Lau D, El-Sayed AM, Ziewacz JE, Jayachandran P, Huq FS, Zamora- Berridi GJ, Davis MC, Sullivan SE. Postoperative outcomes following closed head injury and craniotomy for evacuation of hematoma in patients older than 80 years. J Neurosurg 2012;116:234-45.

4. Araujo JL, Aguiar Udo P, Todeschini AB, Saade N, Veiga JC. Epidemiological analysis of 210 cases of surgically treated traumatic extradural hematoma. Rev Col Bras Cir 2012;39:268-71.

5. Irie F, Le Brocque R, Kenardy J, Bellamy N, Tetsworth $\mathrm{K}$, Pollard C. Epidemiology of traumatic epidural hematoma in young age. J Trauma $2011 ; 71: 847$ 53.

6. Mishra SS, Senapati SB, Deo RC. Traumatic bilateral frontal extradural hematomas with coronal suture diastases. Neurol India 2011;59:940-2.

7. Mayr R, Troyer S, Kastenberger T, Krappinger D, Rosenberger R, Obwegeser A, El Attal R. The impact of coagulopathy on the outcome of traumatic epidural hematoma. Arch Orthop Trauma Surg 2012;132:1445-50.

8. Kiboi JG, Kitunguu PK, Angwenyi P, Mbuthia F, Sagina LS. Predictors of functional recovery in African patients with traumatic intracranial hematomas. World Neurosurg 2011;75:586-91.

9. Naveed D, Bhatti SN, Akbar M, Aurangzeb A. Etiology, presentation and outcome of head injury patients admitted in Ayub Teaching Hospital, Abbottabad. Kust Med J Jul - Dec 2010;2(2):45-8. 
10. Lai Rehman, Azmatullah Khattak, Aamer Naseer, Mushtaq. Outcome of acute traumatic extradural hematoma. J Coll Physicians Surg Pak Dec 2008;18(12):759-62.

11. Khan MJ, Shaukat A, Khalid M, Aziz MA. Surgical management andoutcome analysis of extradural hematoma at Combined Military Hospital Rawalpindi. PAFMJ 2009; 59:70-3.

12. Cheung PS, Lam JM, Yeung JH, Graham CA, Rainer $\mathrm{TH}$. Outcome of traumatic extradural haematoma in Hong Kong. Injury 2007;38:76-80.

13. Leitgeb J, Mauritz W, Brazinova A, Majdan M, Wilbacher I. Outcome after severe brain trauma associated with epidural hematoma. Arch Orthop Trauma Surg. 2013 Feb;133(2): 199-207.

14. Stienen M, Abdulazim A, Hildebrandt G, Gautschi 0 .[Emergency scenario: epidural hematoma evaluation and management]. Praxis 2013 Jan 30;102(3):147-56.

\section{When dictatorship is a fact, revolution}

becomes a right.

\section{Victor Hugo}

